\title{
Sunrise Medical And The Quickie Wheelchair
}

Lisa M. Houts, California State University, USA

\begin{abstract}
This case profiles the Quickie Wheelchair, first developed by a group of entrepreneurs in Fresno, California and now manufactured by Sunrise Medical, the world's leading manufacturer of customized lightweight wheelchairs. Topics such as strategy, product design, location planning, quality control, and just-in-time systems make this case suitable for use in a production and operations management course.
\end{abstract}

Keywords: Lean Production; Just-In-Time; Operations Management; Entrepreneurship; Wheelchair

\section{THE QUICKIE WHEELCHAIR'S BEGINNING}

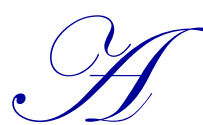

fter Marilyn Hamilton was involved in a tragic hang-gliding accident in 1978, she suddenly found herself wheelchair bound. Weighing 50 pounds, her new steel and vinyl non-adjustable wheelchair was heavy and hard to maneuver. Hamilton, however, still wanted to pursue her love of sports and an active lifestyle. She thought that by using lightweight materials, like the aluminum tubing and nylon found in hang gliders, she could build a more responsive, high-performing chair. Two friends who had previously built hang gliders created her first new wheelchair, and they dubbed it the "Quickie". Amazingly, in 1979, less than a year after her accident, Hamilton and her friends, Jim Okamoto and Don Helman, formed Motion Designs and started making and selling wheelchairs out of a shed in Fresno, California. Revolutionary design made the Quickie the first fully adjustable, ultra-light wheelchair available on the market. Weighing only 25 pounds, this colorful, customizable chair sold for $\$ 1,450$. It was well-suited to the needs of its target market, typically 18-30 year-olds who had previously been active and who wanted to maintain an independent lifestyle. Soon a market also grew for a "sports" chair among wheelchair-bound athletes who sought the Quickie's easy maneuverability and lightweight, foldable design (Case Study, 2009).

Rapid growth followed and by 1985, Motion Designs had annual sales of about $\$ 15$ million (Marilyn Hamilton, 1997). By December of 1986, sales were reported at $\$ 21$ million and Motion Designs had become the U.S. leader in its product categories of custom, ultra-light rehabilitation and sports wheelchairs. Later that year, the owners sold Motion Designs to Richard H. Chandler, founder, chairman, and president of Sunrise Medical. Sunrise, which Chandler began in 1983 (Case Study, 2009), designed, manufactured and marketed health care products. These included power wheelchairs, scooters, beds, crutches, canes, commodes, and bath and pool lifts for the handicapped (Dangerfield, 2012). The Motion Designs acquisition added ultra-light and sports wheelchairs to the product line. Chandler's vision was to create a company that could serve the rapidly aging population and the growing demand for wheelchairs and home health care products that would follow (Case Study, 2009)

\section{THE INTRODUCTION OF JAPANESE MANAGEMENT TECHNIQUES AT SUNRISE}

By 1986, profits were faltering and Chandler took steps to reposition and strengthen the business. During a trip to Japan, he studied Japanese management styles and visited companies like Toyota and Matsushita. Upon returning to the United States, Chandler stopped the expansion-via-acquisition strategy, streamlined the business by divesting unprofitable lines, and reorganized Sunrise employees into autonomous, self-directed teams. At this time, he also began to revamp inventory control, with a goal of keeping only enough parts for the current day's production. In addition, once the products were completed, they were shipped immediately to dealers and customers. These efforts to streamline inventory laid the foundation for Sunrise's transition to a just-in-time system (Derdak, 2011). 
A just-in-time system, however, involves much more than just streamlining inventory. In fact, there are seven types of waste, or "muda", that a J-I-T system tries to minimize. One of these is unnecessary time spent waiting. An interesting example of minimizing this type of waste relates to sales and manufacturing at Sunrise. When a dealer called in a product order, there was an average wait time of four and a half minutes before a live sales representative could answer the phone. About 23 percent of callers grew tired of waiting and hung up before placing an order. In response, Sunrise redesigned the process and reduced the hang-up rate to just two percent. That year, sales grew by 30 percent; in part, the growth was due to better customer service and reduced call-waiting times. At the same time, a unique corporate culture was shaped to improve relationships between employer and employee and to reduce other kinds of waste. In addition, production techniques improved so previously expensive wheelchair options became affordable standard features, and customers responded positively. They were also excited about the many variations of back height, seat depth, seat width, and color choices from which they could choose. By the end of 1989 the fruits of these labors were paying off, and revenues had grown to over $\$ 152$ million (Derdak, 2011).

\section{LEADERSHIP AND STRATEGY UPDATES}

Over the years, leadership and strategy changed. For a period of time, Sunrise again focused on growth through acquiring a variety of other businesses in the home health care industry. More recently, however, divisions like long-term care, respiratory and sleep therapy products, and commodity products such as walkers and crutches have been divested to improve efficiencies, competitiveness, and profitability. Sunrise is now under the leadership of President and CEO, Thomas Rossnagel. In a press release dated April 1, 2010, Rossnagel stated, "Our goal is to become the most efficient provider of premium mobility products and services in the U.S. market. We have truly reinvented ourselves in the past two years here in the U.S. The positive feedback we have received from our customers confirms we are on the right track" (Sunrise Consolidates, 2010, p. 1). By the fiscal year-end of June 2010 , Rossnagel reported record global revenues that topped $\$ 370$ million. This came largely as the result of successful new product introductions, the completion of a global rebranding project, and a number of cost improvement programs. Rossnagel reflected, "We have come a long way in FY10...Sunrise Medical now is successfully repositioned as the leading premium mobility company" (Sunrise Medical FY10, 2012, p. 1). As the world's leading manufacturer of customized lightweight wheelchairs, Sunrise has a lot to be proud of. Indeed, in global sales in the home health care product market, Sunrise ranks second only to Invacare. Furthermore, in the ultralight sports wheelchair market, it is Invacare's only significant competitor (Kooner, 2011).

\section{FACILITIES AND LOCATIONS}

Sunrise now calls Fresno, California home to its North American headquarters. European headquarters are located in Malsch, Germany. In addition to manufacturing wheelchairs in the United States, Sunrise also has manufacturing facilities in Mexico, Germany, the United Kingdom, Spain, and China. Products are then distributed in over 90 countries. Approximately 1,600 people are employed worldwide, with about 350 working in Fresno. Fresno workers focus on research and development, product design, manufacturing, and customer service (Corson, 2011). Sunrise's manufacturing facilities typically serve a designated geographic area. Those in the United States primarily make chairs to be sold in this country. Wheelchairs for the European market are usually made in Europe. This geographic focus is necessary because the aesthetics and functionality requirements of the products differ from one part of the world to another. Different markets have different preferences and product categories. Product coding, testing standards, and funding requirements vary as well (Kooner, 2011).

Rossnagel describes Sunrise's strategies for the future by saying, "We are thinking globally, but executing on a regional basis" (Sunrise's Rossnagel, 2009, p. 2). At the same time Sunrise is exiting less profitable product lines in the U.S, the same types of products may be doing well in Europe. For example, Sunrise sells scooters in Europe but has not been able to compete well in that product segment in the U.S. Rossnagel adds that for all of its operations, regardless of where they are, Sunrise must set its sights on being within the top three competitors in any segment in which it competes. "The regional strategies that lead to this goal can vary", he explains, "and there is nothing wrong with this, in my opinion" (Ibid). 


\section{PRODUCT DESIGN AND PRODUCT LINES}

Sunrise Medical's brands include Quickie, Zippie, Breezy, and Jay. Differentiation based on quality and customization are key to Sunrise's strategy. Sunrise's president of U.S. commercial operations further articulated the company's strategy from a product design standpoint, saying that “....in the segments we participate in, we will offer a premium product in regards to functionality, appearance, and durability. Furthermore, we will provide premium services for our dealers, clinicians, and end-users" (Sunrise Consolidates, 2010, p. 2).

Today, Sunrise manufactures and supplies wheelchairs, accessories, and replacement parts for both institutional and home use. It also produces Jay's brand of seat cushions and backrests for wheelchairs. Its product lines include manual wheelchairs, pediatric and positioning products, sports wheelchairs, and power chairs. The pediatric line, often used for institutional care, gives caregiver interface with the wheelchair special consideration in product design and functionality. Sports chairs are designed so that wheelchair-bound individuals can participate in tennis, basketball, baseball, marathons, snow skiing, and other active pursuits. Power chairs are motorized and can be controlled in a variety of ways, ranging from a simple joystick to head controls to a "sip and puff" system. In the "sip and puff" system, the person in the chair directs its movement by blowing one, two, or three puffs of air into a tube which translates those instructions into directional controls. Sunrise is the market leader in manual wheelchairs and is gaining momentum in the power wheelchair market where it ranks third or fourth (Kooner, 2011).

All design is done in-house by Sunrise's product design team with input from other functional areas to streamline the process. Wheelchairs go from design and engineering to testing, where new prototypes undergo rigorous screening to see how long parts will last and which areas of the chair are susceptible to breakage or damage. For instance, chairs are subjected to a "drop" test. A prototype wheelchair is dropped multiple times from a height of four inches with a human-weighted mannequin seated in it. Also, a track which simulates driving the chair over varying terrains is used to further test the chair's durability. Parts which are found to break or wear out too soon are sent back to engineering for redesign. Only chair designs that can meet Sunrise's tough standards for quality will be put into production (Zellet, 2011).

\section{FRESNO'S JUST-IN-TIME MANUFACTURING SYSTEM}

In Fresno all of Sunrise's wheelchairs are custom made. Individually prescribed chairs are ordered for customers by dealers, who can call or fax customer service or use the online configurator. Each order involves many choices related to the sizing, styling, comfort, and functionality of the chair. Central to Sunrise's lean production is its pull-based production system. Unlike in a traditional push system, where parts or products are ordered and produced whether or not there is immediate need for them, Sunrise's pull system orders parts and produces products only when an order is actually placed. The process begins when an order is called in and then released to production. Demand for each subassembly, component or raw material is triggered upstream. Notices are sent to suppliers who will build or package parts. They may have prebuilt the parts ahead of time, or they may fabricate or assemble them that day. Items are then shipped so Sunrise will receive them by the next morning. The suppliers that Sunrise relies on are a mix of local and international businesses. Some parts, such as the Jays custom seating, are fabricated internally (Kooner, 2011). Lead times within the facility are strictly monitored and maintained, as a delay in one area creates a ripple effect throughout the rest of the production system. Each morning at $5 \mathrm{am}$ a delivery truck arrives from the company's plant in Mexico with the parts needed to support the day's production. Inventory is kept low, and in general, no more than 48 hours worth of supplies are on hand for these parts in the Fresno facility. If a defective or damaged batch is received, decisions must be quickly made about whether to scrap or rework the parts. The flow of the demand-pull system is regulated by kanban, or signals. At the Fresno facility, when a worker uses a part, he scans its code and a kanban is created which signals the need for replenishment. A stocker pulls the needed parts, puts them on carts, and delivers them to their destinations every hour or two. He then returns with his cart empty, ready to begin the process again. This allows workers to have enough work-in-process inventory to use in their current production without having excessive amounts of inventory on hand (Zellet, 2011).

Sunrise Medical's J-I-T system seeks to reduce waste wherever possible. One technique pertains to how inventory is handled when it arrived from suppliers. Although some items are stocked in a warehouse when 
received from the delivery trucks, others bypass the warehouse entirely, going directly to point of use in assembly. This saves time and storage space and minimizes how often each item is handled. Although the focus is on keeping inventory low, sometimes it is not possible to order every part as needed. Some parts are stocked in house because replenishment takes time. Parts shipped from China, for instance, require several weeks in transit. Also, when placing orders with external suppliers at certain times of day, Sunrise accrues demand for a certain component and orders those items all at once, rather than as it receives each individual wheelchair order (Kooner, 2011).

Internally, Sunrise may also lump together certain portions of the day's order to make better use of set ups and to minimize the number of changeovers needed. One example involves the painting process. Currently, because the painting process has a seven to ten minute changeover time, and because Sunrise offers 25 different colors to its customers, Sunrise runs the same color once or twice a day, painting all items that have been custom ordered with those colors. However, the need to batch is contrary to the ideal lot size of "one" that a just-in-time system pursues. With the installation of a new painting process, a lot size of one will become a reality, enabling color changes for individual customer orders. Three booths, each able to paint two colors, will allow greater flexibility to the system as well as lower levels of painted parts inventories stored on racks near the painting area. Although compared to many organizations, the amount of inventory on the racks is already minimal, to Sunrise it represents waste. For instance, a small stock of some painted aluminum parts is on hand for use in the wheelchairs. This includes some colors that are no longer made but that must be kept for replacement parts that customers order. However, some of these seldom used colors are gathering dust. With the new system, it will no longer be necessary to store these; rather, they can be painted as needed when customers order the replacement parts (Zellet, 2011).

About 250 of the 350 Fresno employees work in the manufacturing area (Corson, 2011). As in a typical lean system, workers are cross-trained to increase flexibility and responsiveness. If, for instance, more help is needed in the production of power wheelchairs, workers from the Jay's seating area may come over to help. This allows Sunrise to operate with a smaller full-time crew (Zellet, 2011).

Quality is carefully monitored to ensure that the just-in-time system will run smoothly. Employees often verify their own work first and then quality assurance specialists come in at certain predetermined points to doublecheck things. For instance, the power wheelchairs that Sunrise produces are typically high end, individually customized rehabilitation products. This sets them apart from the mass-produced, less expensive power chairs with lower functionality that are featured by competitors on day-time television advertising (Kooner, 2011). To maintain the high level of quality that Sunrise expects from all its products, 100 percent inspection of finished products in the power wheelchair assembly area is the norm. Each completed wheelchair is tested by a person who drives it around and tests all of the various features and components. This is done in addition to inspections of individual parts earlier in the process. For instance, the seat cushions that are installed in the power chairs have already undergone 100 percent inspection before leaving that area of the plant (Zellet, 2011).

The cumulative lead time for making a chair is typically about five days. After that, modes of shipment include ground and air, so delivery time can vary from next day to five days. On-time delivery is a key part of Sunrise's strategy. The overall goal is to have at least $95 \%$ of all orders delivered on time. Each production area has its own rate of success in meeting this goal. The wheelchair production unit consistently hits 95 percent (Zellet, 2011). The seating division is very proud of the 99 percent on-time delivery rate that it typically maintains. This is a remarkable feat, especially since each of the 60-110 seats made here daily is specially cut and assembled based on what each customer wants, using the "JAY Your Way" custom ordering system. Foam used inside the seat cushions, for instance, comes in varying widths and textures, and customers can specify exactly what they prefer. Fluid inserts, pads, and cutouts are frequently requested for customized comfort (Sunrise Medical Announces, 2011).

\section{CONCLUSION}

The Quickie wheelchair has come a long way since it was created in the late 1970's. Manufacturing techniques have changed from those of a small, entrepreneurial business to those of Sunrise Medical's world-class production facilities, employing the best of lean production techniques to deliver high quality, customized wheelchairs to loyal consumers around the world. 


\section{AUTHOR INFORMATION}

Lisa M. Houts, Lecturer, California State University, Fresno, May 1990 - present; Courses taught: Production Operations Management, Organizational Behavior, Managerial Ethics; E-mail: lisahouts@csufresno.edu

\section{REFERENCES}

1. "Case Study: Marilyn Hamilton and Motion Designs," Innovation and Entrepreneurship, http://knowlege.wharton.openn.edu/10000women/article.cfm?articleid+6103, May 14, 2009, pp. 1-2.

2. Corson, Brent; Director of Human Resources; Sunrise Medical; Personal Interviews, December 13, 2011.

3. Dangerfield, Alan; Manufacturing and Engineering Services, Senior Manager, Sunrise Medical; Personal Interview, February 9, 2011.

4. Derdak, Thomas, "Sunrise Medical Inc.," http://www.answers.com/topic/sunrise-medical-inc, referenced September 26, 2011, pp. 1-6.

5. Kooner, Avtar; Vice President of Manufacturing Operations, Sunrise Medical; Personal Interview, October 13, 2011.

6. "Marilyn Hamilton, A Play In Three Acts," http://www.newmobility.com/articleViewIE.cfm?id=41\&srch+products\%20equipment, September 1997, pp. 1-5.

7. "Quickie signs 35 distributors, enters new sports market - Sunrise Medical Inc. Quickie Designs Inc.," http://findarticles.com/p/articles/mi_m3498/is_n4_v56/ai_14110094, Health Industry Today, April 1993, pp. 1-2.

8. "Sunrise Consolidates Plant Functions: 'We Have Reinvented Ourselves,' Rossnagel Says," http://www.homecaremag.com/news/sunrise-reinvented-201004-1; April 1, 2010, pp. 1-2.

9. "Sunrise Medical FY10 Review and FY11 Outlook Under the Leadership of Thomas Rossnagel, President and CEO, September 20, 2010, pp. 1-3.

10. "Sunrise Medical Announces Launch JAY Your Way Custom Modification Program," http://www.sunrisemedical.com, December 13, 2011, pp. 1-2.

11. "Sunrise's Rossnagel: A Year of Change and More Ahead," http://www.homecaremag.com/mobility/wheelchairs-scooters/change-sunrise-medical-rossnagel-20090629, June 29, 2009, pp. 1-3.

12. Zellet, Christian; Manufacturing Manager, Sunrise Medical; Personal Interview/Plant Tour, November 18, 2011. 


\section{TEACHING NOTES}

\section{Does Sunrise Medical use a differentiation or cost leadership strategy? What production and design choices are used to support this strategy?}

Sunrise Medical uses a differentiation strategy, focusing on superior quality, variety, flexibility, service, and on-time delivery. As stated by Sunrise's president of U.S. commercial operations, “...in the segments we participate in we will offer a premium product in regards to functionality, appearance, and durability. Furthermore, we will provide premium services for our dealers, clinicians, and end-users" (Sunrise Consolidates, 2010, p.2). This statement defines core competencies and strategies at Sunrise. Superior quality comes as a result of extensive testing in the design phase as well as the quality control techniques that are in place once the wheelchair goes into production. Variety and flexibility are high, with each wheelchair being made to the individualized specifications of the customer. This is facilitated by the just-in-time production techniques that are in place. Outstanding customer service and on-time delivery of chairs and replacement parts are also made possible by the just-in-time manufacturing system and the focus on customer satisfaction.

\section{What elements of just-in-time are seen at Sunrise Medical?}

Maintaining low levels of incoming parts, work-in-process, and finished products is key to Sunrise Medical's just-in-time system. Kanban cards are used to cue restocking of parts. Moving some inventory directly from incoming trucks to the production line also streamlines the process, minimizing needs for storage space and cutting down on time spent handling inventory. Cross-trained production workers add flexibility and responsiveness to the system and allow for a more efficient use of the workforce. Minimization of waiting time for customers who are calling in orders is also emphasized.

\section{Where in the process is quality monitored? What approaches are used?}

Quality is monitored for inputs, the transformation process, and outputs. Inputs (incoming materials and parts) are inspected before being released into the production process. During the transformation process, partially completed wheelchairs or parts, such as cushions, are verified by the workers who made them. In addition, specially designated quality inspectors check for conformance at certain points in the process. Outputs, the finished wheelchairs, are checked as well. Power chairs, for instance, are tested by an employee who drives them around and verifies that all parts are functioning as they should.

\section{How does a just-in-time strategy affect or interact with issues related to quality?}

In a just-in-time system, the focus on minimizing waste typically leads to improved quality. For instance, as inventory levels are lowered over time, problems are revealed and must be overcome in order for the system to operate efficiently. If supplier lead time varies, if incoming materials have quality problems, if forecasting is inaccurate, or if preventive maintenance is lacking, these problems will become more pronounced when inventory levels are lower. Since fewer inventory items are available to cushion or cover up these problems, they take a more immediate toll on the flow of the system. Thus, lowering inventory requires that more and more problems be fixed, typically resulting in fewer disruptions to production and higher quality of both the production process and products. At Sunrise, another example pertained to customer waiting time when calling in an order. Reducing waiting time, also considered a form of waste, resulted in improved quality of customer service. 